\title{
Characteristics and outcomes of patients with dyspnoea as the main symptom, assessed by prehospital emergency nurses- a retrospective observational study
}

\author{
Wivica Kauppi ${ }^{1,2^{*}}$ (D) Johan Herlitz ${ }^{1,2}$, Carl Magnusson ${ }^{1,3}$, Lina Palmér ${ }^{2}$ and Christer Axelsson ${ }^{1,2}$
}

\begin{abstract}
Background: Dyspnoea (breathing difficulty) is among the most commonly cited reasons for contacting emergency medical services (EMSs). Dyspnoea is caused by several serious underlying medical conditions and, based on patients individual needs and complex illnesses or injuries, ambulance staff are independently responsible for advanced care provision. Few large-scale prehospital studies have reviewed patients with dyspnoea. This study aimed to describe the characteristics and final outcomes of patients whose main symptom was classified as dyspnoea by the prehospital emergency nurse (PEN).

Methods: This retrospective observational study included patients aged $>16$ years whose main symptom was dyspnoea. All the enrolled patients were assessed in the south-western part of Sweden by PENs during January and December, 2017. Of 7260 assignments (9\% of all primary missions), 6354 fulfilled the inclusion criteria. Analysis was performed using descriptive statistics, and the tests used were odds ratios and Kaplan-Meier analysis.

Results: The patients mean age was 73 years, and approximately 56\% were women. More than 400 different final diagnostic codes (International Statistical Classification of Diseases and Related Health Problems [ICD]-10th edition) were observed, and $11 \%$ of the ICD-10 codes denoted time-critical conditions. The three most commonly observed aetiologies were chronic obstructive pulmonary disease (20.4\%), pulmonary infection (17.1\%), and heart failure (15\%). The comorbidity values were high, with $84.4 \%$ having previously experienced dyspnoea. The overall 30-day mortality was $11.1 \%$. More than half called EMSs more than $50 \mathrm{~h}$ after symptom onset.
\end{abstract}

Conclusions: Among patients assessed by PENs due to dyspnoea as the main symptom there were more than 400 different final diagnoses, of which $11 \%$ were regarded as time-critical. These patients had a severe comorbidity and $11 \%$ died within the first 30 days.

Keywords: Dyspnoea, Epidemiology, Aetiology, Major incidents, Prevention, Emergency medical service, Prehospital emergency nurse, Ambulance

\footnotetext{
* Correspondence: wivica.kauppi@hb.se

'PreHospen- Centre for Prehospital Research, Faculty of Caring, Work Life and Social Welfare, University of Borås, SE- 50190 Borås, Sweden

${ }^{2}$ Faculty of Caring Science, Work Life and Social Welfare, University of Borås, Borås, Sweden

Full list of author information is available at the end of the article
}

(c) The Author(s). 2020 Open Access This article is licensed under a Creative Commons Attribution 4.0 International License, which permits use, sharing, adaptation, distribution and reproduction in any medium or format, as long as you give appropriate credit to the original author(s) and the source, provide a link to the Creative Commons licence, and indicate if changes were made. The images or other third party material in this article are included in the article's Creative Commons licence, unless indicated otherwise in a credit line to the material. If material is not included in the article's Creative Commons licence and your intended use is not permitted by statutory regulation or exceeds the permitted use, you will need to obtain permission directly from the copyright holder. To view a copy of this licence, visit http://creativecommons.org/licenses/by/4.0/ The Creative Commons Public Domain Dedication waiver (http://creativecommons.org/publicdomain/zero/1.0/) applies to the data made available in this article, unless otherwise stated in a credit line to the data. 


\section{Background}

Dyspnoea (breathing difficulty) is among the most commonly cited reasons for contacting emergency medical services (EMSs) [1]. The American Thoracic Society defines dyspnoea as "a subjective experience of breathing discomfort that consists of qualitatively distinct sensations that vary in intensity" [2]. It manifests itself in various ways such as shortness of breath, air hunger, and chest tightness [3]. Dyspnoea is caused by several medical conditions $[4,5]$, and respiratory failure is among the most severe time-critical conditions for which the provision of immediate prehospital care by EMSs can have a highly valuable impact [6].

In Sweden, prehospital emergency nurses (PENs) have an important role in the assessment and triaging of dyspnoea patients at the scene. The treatment of dyspnoea begins with the management of the underlying condition, due to which the diagnosis of acute dyspnoea is crucial in EMS settings to ensure the provision of appropriate treatment and care [7]. Patients with dyspnoea constitute a complex group, as the presence of additional health problems makes it difficult to identify the underlying cause of the condition. In addition to the physiological perspective, severe anxiety and fear are observed commonly in connection with dyspnoea. This denotes that PENs have the responsibility of providing care aimed at increasing patients strength and focusing on their existential needs [8-10]. Previous studies have described the epidemiology and outcomes of patients with dyspnoea who are transported by EMSs to emergency departments (EDs) in Denmark, Australia/New Zealand and the United States $[8,11,12]$. However, few large-scale EMS studies have been conducted in such settings till date. In the present study, we aimed to describe the characteristics and final outcomes, overall and in relation to sex of patients receiving care from PENs and whose main symptom was dyspnoea.

\section{Methods \\ Design}

A quantitative, exploratory, descriptive design was employed based on a consecutive retrospective review of EMS and hospital records. The study included all patients over a one-year time-period who called the emergency number (112) in Sweden, had an ambulance dispatched and were assessed by the prehospital emergency nurses (PENs) with the main symptom of dyspnoea.

\section{Settings \\ Population}

The study was conducted within two EMS organisations, which together include 16 ambulance stations in the southwestern part of Sweden. The two EMS organisations cover a combined area of $7400 \mathrm{~km}^{2}$, with a population of 962,000 inhabitants in urban, suburban, and rural areas. During 2017, the two EMS organisations had 123,614 ambulance missions with a priority level of 1 to 3 . Of these, 87,611 missions involved an initial patient assessment defined as the primary mission (Fig. 1).

\section{Competence of Swedish ambulances, and the associated guidelines and triage system}

Since 2005, all ambulances in Sweden have at least one registered nurse and one ambulance technician [13]. A majority of all such nurses have completed a three-year nursing course followed by a one-year Master's course focusing on prehospital emergency care and have the professional title 'PEN'. PENs provide assessment and treatment according to national and local guidelines.

In order to assess and prioritise patients degree of prehospital care required, PENs perform triage classification according to the Rapid Emergency Triage and Treatment System for adults (RETTS- A) [14]. RETTS-A codes are divided into the following types: 1) vital signs (VS) and 2) 53 emergency signs and symptoms (ESS) codes [see Additional file 1: Red and orange VS and ESS code 04, dyspnoea]. Both types allow for the allocation of patients separately to a severity/triage level in which the highest level is used for the final assessment. The severity/triage level is assigned one of five different colours (red, orange, yellow, green, and blue) according to the time from assessment to the time a patient must be seen by a physician. Red and orange indicate the most urgent cases whereas yellow and green denote the absence of individual medical risk even if patients are made to wait to undergo physician assessment. The colour blue is not used in the prehospital triage. In ESS code 04 (dyspnoea as the main symptom), it is mandatory for the PENs to evaluate ECG in all patients. In addition of all prehospital severe ill patients, it is also mandatory to evaluate the P-Glucose level.

\section{Inclusion and exclusion criteria}

The inclusion criteria were as follows: 1) a primary mission in which a patient (or e.g. a family member that represents the patient) calls the dispatch centre, an ambulance is dispatched and 2) the assignment of an ESS code of 04 (dyspnoea) is made by the PEN. The exclusion criteria were as follows: 1) lack of a personal identity number, 2) transportation to hospitals outside the research area, 3) age $<16$ years, 4) duplicate EMS records, 5) missing record or lack of information, 6) incorrect triage (ESS), and 7) secondary transport use. A total of 7260 patients were initially identified from the sample (9\% of all assignments). After a manual review, 908 patients were excluded due to various exclusion criteria, and a total of 6354 patients were finally included in the study (Fig. 1). Among the 6354 patients, a total of 


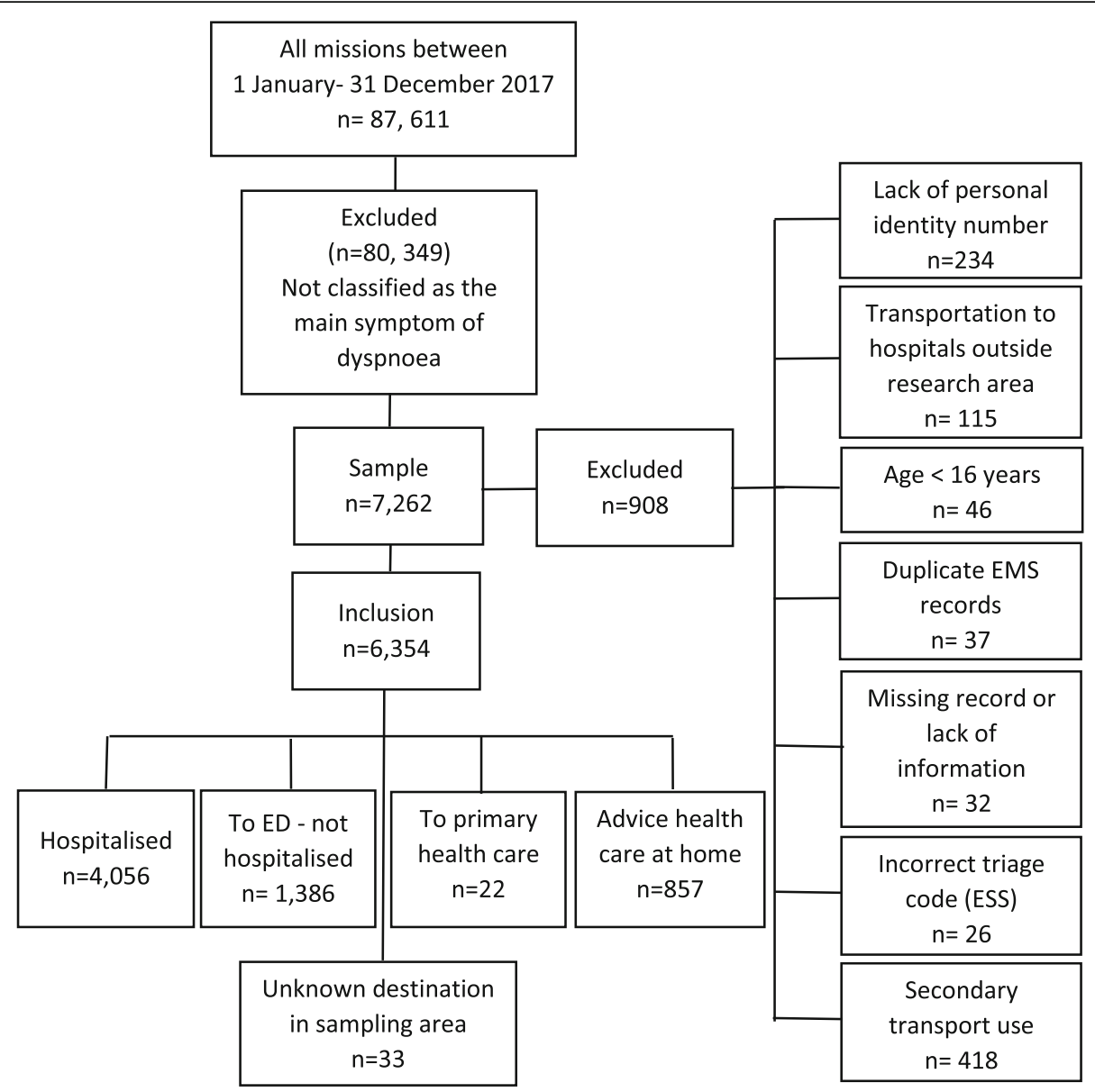

Fig. 1 Flow chart of the studied patients, assessed as the main symptom of dyspnoea

3665 patients had one EMS contact during the study period and 2689 patients had multiple contacts. A total of 4587 unique patients were included in the survival analysis of which 922 patients were randomly selected from the patients with multiple contacts.

\section{Endpoints}

The primary endpoint was the aetiology according to the final diagnosis. Secondary endpoints were comorbidity according to patients previous history and the 30- day mortality. Tertiary endpoints were the patients delay time from symptom onset until calling for EMS and clinical findings on arrival of PENs.

\section{Data collection}

The patients in this study were consecutively included by assignment through an EMS record database (Ambulink) and followed-up by hospital records (Melior) according to the directions for inclusion and exclusion. Ambulink contains the RETTS-A triage classification and Melior contains the International Classification of Diseases (ICD) code. Medical history and final diagnoses were categorised using the ICD-10 which comprises 22 chapters (I-XXII). In all the ambulances, only 12 lead ECG was used. In order to achieve the best possible data quality, data on ECG interpretations were collected first from prehospital records, second from ED notes, and third, in cases in which no interpretation was documented but an ECG was recorded, by the author (WK). ECG deviations comprise atrial fibrillation/flutter, ST-elevation, ST-depression, T-wave inversion, and left bundle branch block. Other deviations include AVblock I, II, III, ectopic atrial rhythm/tachycardia, and ventricular tachycardia. P-glucose levels were measured through a capillary test performed by the PEN, and a value $\geq 9.5 \mathrm{mmol} / \mathrm{l}$ was defined as high [15].

Time-critical conditions are defined as conditions where prompt management and medical interventions are crucial to avoid severe complications and early death $[16,17]$.

These were defined by our research group consisting of a cardiologist and number of PENs based on the available literature and clinical experience. This definition has been previously described [16]. However, a few further diagnoses (e.g. acute respiratory failure with 
hypercapnia or hypoxia, ketoacidosis and lactacidosis) fulfilling the above criteria appeared in the analyses of the present study cohort and have therefore been added.

\section{Statistics}

In the tables, results are presented as number (percentage), median (25th, 75th percentiles), or mean (standard deviation). For two-group comparisons, crude odds ratios with their correspondent confidence intervals were calculated. A Kaplan-Meier survival curve stratified by sex was plotted (Fig. 2), while the lifelines survival function was used to report differences by sex for 30-day mortality. All tests are two-sided, and due to the number of tests performed, $p$-values $<0.01$ were considered significant. Confidence intervals computed at the $99 \%$ level were used. Data processing and statistical analyses were performed using SPSS version 24 (Armonk, NY, USA: IBM Corp.) and Python version 3.7 (Python software foundation) with lifelines package (Cameron Davidson-Pilon, Jonas Kalderstam, Paul Zivich, et al. CamDavidsonPilon/lifelines: v0.23.9. 2020).

\section{Results}

Totally, 7262 EMS missions fulfilled the inclusion criteria, and 908 cases (13\%) were excluded due to reasons shown in Fig. 1. Overall, patients with the ESS code 04 (dyspnoea as the main symptom) conformed 9\% of all primary EMS missions and more than $60 \%$ of those patients were hospitalised (Fig. 1).

\section{Age, sex, and previous history}

The patients' mean age was 73 years, and $56 \%$ of them were women. A majority (84.4\%) had previously experienced dyspnoea. A large proportion had a history of cardiovascular disease including hypertension (46.5\%), heart failure (30\%), atrial fibrillation (29\%), ischemic heart disease (26\%). Furthermore, $47.5 \%$ had a history of pulmonary disease, 18.8\% had diabetes and 19.4\% had cancer. Men had a higher prevalence of previous heart disease, diabetes and renal disease whereas women had a higher prevalence of previous pulmonary disease, system disease and psychiatric disease (Table 1).

\section{Symptoms and clinical findings}

In all, $23.1 \%$ of the patients had pain, $1.2 \%$ had syncope, and $1.6 \%$ showed alcohol/drug-related issues. Abnormal vital parameters were seen with the following rates (according to the RETTS-A): respiratory rate $<8 / \mathrm{min}$ or $>$ $25 / \min (48.7 \%)$, oxygen saturation $<90 \%(35.2 \%)$, heart rate $<40 / \mathrm{min}$ or $>120 / \mathrm{min}(11.5 \%)$, systolic blood pressure $<90 \mathrm{mmHg}(1.8 \%)$, body temperature $<35$ or $>41 \mathrm{de}-$ grees $(0.5 \%)$, and degree of consciousness $>$ RLS 2 (1.6\%). An ECG was recorded in $74 \%$ of the cases; $70.8 \%$ of them showed a sinus rhythm, whereas $22.8 \%$ showed atrial fibrillation/flutter. Signs of possible myocardial ischemia were revealed as ST-elevation (2.5\%), ST-depression (13.9\%), T-wave inversion (9.5\%), and left bundle branch block (6\%). P-glucose levels were measured in $31.3 \%$ of the cases, of whom $37.6 \%$ showed elevated values. Men had more often deviation of the systolic blood pressure and atrial fibrillation than women (Table 2).

\section{Distribution of patients across the 22 major ICD-10 code groups}

The three most commonly observed disease groups were: diseases of the respiratory system (49.1\%); diseases




Table 1 Age, sex and previous history

\begin{tabular}{|c|c|c|c|c|c|c|}
\hline \multirow[b]{2}{*}{$\mathrm{n}$} & \multirow{2}{*}{$\begin{array}{l}\text { All patients } \\
6354\end{array}$} & \multirow{2}{*}{$\begin{array}{l}\text { Women } \\
3538\end{array}$} & \multirow{2}{*}{$\begin{array}{l}\text { Men } \\
2816\end{array}$} & \multirow[b]{2}{*}{ All } & \multicolumn{2}{|l|}{ Missing } \\
\hline & & & & & Women & Men \\
\hline \multicolumn{7}{|l|}{ Age - years } \\
\hline Mean $( \pm S D)$ & $72.9(17.5)$ & $73.3(18.1)$ & $72.5(16.6)$ & & & \\
\hline Median (25th,75th percentile) & $77(66,86)$ & $78(67,86)$ & $76(66,85)$ & & & \\
\hline \multicolumn{7}{|l|}{ Previous history - $\mathrm{n}(\%)$} \\
\hline Dyspnoea & $4971(84.4)$ & $2766(84.0)$ & $1.07[0.89,1.29]^{a}$ & 467 & 247 & 220 \\
\hline Pulmonary disease ${ }^{b}$ & $2966(47.5)$ & $1762(50.6)$ & $0.76[0.66,0.86]$ & 116 & 59 & 57 \\
\hline Hypertension & $2948(46.5)$ & $1718(48.6)$ & $0.82[0.72,0.94]$ & 8 & 5 & 3 \\
\hline Heart failure & $1894(30.0)$ & $961(27.4)$ & $1.32[1.15,1.52]$ & 38 & 27 & 11 \\
\hline Atrial fibrillation & $1838(29.0)$ & $945(26.8)$ & $1.27[1.10,1.47]$ & 14 & 8 & 6 \\
\hline Ischaemic heart disease & $1642(26.0)$ & $785(22.3)$ & $1.54[1.33,1.79]$ & 40 & 16 & 24 \\
\hline Psychiatric disorder ${ }^{c}$ & $1337(21.2)$ & $862(24.5)$ & $0.63[0.53,0.74]$ & 34 & 20 & 14 \\
\hline Cancer & $1226(19.4)$ & $669(19.0)$ & $1.06[0.90,1.25]$ & 23 & 15 & 8 \\
\hline Diabetes & 1190 (18.8) & $550(15.6)$ & $1.60[1.35,1.89]$ & 12 & 7 & 5 \\
\hline Renal disease & 759 (12.0) & $310(8.8)$ & $1.97[1.61,2.42]$ & 12 & 8 & 4 \\
\hline System disease & $393(6.2)$ & $286(8.1)$ & $0.45[0.33,0.61]$ & 17 & 12 & 5 \\
\hline Other disease ${ }^{d}$ & 4412 (69.5) & $2458(69.6)$ & $1.00[0.87,1.15]$ & 8 & 4 & 4 \\
\hline
\end{tabular}

adds ratio and $99 \%$ - confidence interval

${ }^{\mathrm{b}}$ Chronic obstructive pulmonary disease, asthma bronchiale, other pulmonary disease

'Panic disorder, anxiety disorder, depression, bipolar disease, schizofrenia, other psychiatric disorder

${ }^{d}$ Other disease: e.g. peripheral vascular diseases, other heart conditions, previous pulmonary embolism

of the circulatory system (23.1\%); and symptoms, signs, and abnormal clinical findings not elsewhere classified (13.4\%). Women had more often a respiratory disease (Table 3).

\section{Distribution of patients according to the final diagnosis (ICD-10 code) among groups more than 30 patients}

The patients showed 473 different ICD-10 codes pointing to the primary aetiology. The three most commonly observed aetiologies were Chronic Obstructive Pulmonary Disease (COPD) (20.4\%), pulmonary infection (17.1\%), and heart failure (15\%). Totally, $11 \%$ of the ICD-10 codes showed time-critical conditions. After combining these ICD-10 codes, the three most common conditions were cardiovascular disease, followed by infection and pulmonary disease. Women more often had pulmonary disease (Table 4).

\section{Mortality}

The overall 30-day, and 1-year mortality values were 11.1 , and $21.5 \%$, respectively. Men had a higher 1 -year mortality than women $(p<0.005)$ (Fig. 2$)$. The three most common final diagnoses among all patients who died within 30 days were pneumonia, followed by heart failure and COPD with acute exacerbation. The three most common final diagnoses among patients with timecritical conditions who died within 30 days were stroke, sepsis followed by acute respiratory insufficiency.

\section{Discussion}

In this study, dyspnoea was classified as the main symptom in approximately $9 \%$ of all the EMS-assigned patients, similar to previous findings $[1,9,12]$. The most novel information was that among patients with dyspnoea there were more than 400 different final diagnoses. (ICD-10 codes) and $11 \%$ of them were assessed as time critical. Many of the patients had a severe comorbidity and $11 \%$ were dead within 30 days. Despite this, only half of the patients dialled 112 within $50 \mathrm{~h}$ after onset of symptoms.

The three most commonly observed disease groups were those of the respiratory system; those of the circulatory system; and symptoms, signs, and abnormal clinical findings not elsewhere classified. This finding is similar to that of a recent Danish study [8], with the exception for diseases of the circulatory system, which were more frequently noted in our study (23\% versus $13 \%)$. Moreover, the three most commonly observed aetiologies were COPD (20\%), pulmonary infection (17\%), and heart failure (15\%). In the United States, a lower frequency of COPD (13\%) was observed [12], whereas a study from Australia/New Zealand showed higher rates of pulmonary infections (23\%) and heart failure (20\%) [11].

The patients in whom dyspnoea was the main symptom represent an older population (median age 77 years) with a high comorbidity. Such findings have also been 
Table 2 Symptoms and clinical findings

\begin{tabular}{|c|c|c|c|c|c|c|}
\hline & All patients & Women & Men & & Missing & \\
\hline$n$ & 6354 & 3538 & 2816 & All & Women & Men \\
\hline \multicolumn{7}{|l|}{ Time interval - median hh:mm } \\
\hline Symptom onset - call for EMS & $51: 08(3: 57,145: 02)$ & $50: 58[47: 49,55: 18]$ & $51: 11[47: 47,55: 59]$ & 438 & 245 & 193 \\
\hline \multicolumn{7}{|l|}{ Symptoms - n(\%) } \\
\hline Pain & $1402(23.1)$ & $806(23.9)$ & $0.91[0.78,1.07]^{\mathrm{b}}$ & 292 & 162 & 130 \\
\hline If yes, VAS median ${ }^{a}$ & $4(2,6)$ & $3[2,4]$ & $4[3,5]$ & 1149 & 660 & 489 \\
\hline Syncope & $77(1.2)$ & $47(1.3)$ & $0.80[0.44,1.47]$ & 24 & 14 & 10 \\
\hline Affected by alcohol, drugs & $103(1.6)$ & $46(1.3)$ & $1.57[0.94,2.63]$ & 36 & 17 & 19 \\
\hline \multicolumn{7}{|l|}{ Vital signs; first recording - median ${ }^{c}$} \\
\hline Respiratory rate (breaths/min) & $25(20,32) 48.7$ & $25(20,32) 49.1$ & $0.96[0.84,1.01]$ & 137 & 70 & 67 \\
\hline Oxygen saturation (\%) & $93(86,97) 35.2$ & $93(85,97) 36.0$ & $0.92[0.81,1.06]$ & 120 & 55 & 65 \\
\hline Heart rate (beats/min) & $92(80,110) 11.5$ & $94(80,110) 11.7$ & $0.95[0.77,1.17]$ & 122 & 58 & 64 \\
\hline Systolic blood pressure (mmHg) & $140(120,160) 1.8$ & $140(120,160) 1.2$ & $2.15[1.30,3.57]$ & 236 & 132 & 104 \\
\hline Diastolic blood pressure (mmHg) & $80(70,90) 0.3$ & $80(70,90) 0.3$ & $1.26[0.37,4.25]$ & 870 & 482 & 388 \\
\hline Body temperature $\left({ }^{\circ} \mathrm{C}\right)$ & $37.0(36.6,37.4) 0.5$ & $37.0(36.6,37.5) 0.5$ & $1.34[0.55,3.29]$ & 234 & 128 & 106 \\
\hline Degree of consciousness (RLS) & $1(1,1) 1.6$ & $1(1,1) 1.7$ & $0.91[0.51,1.60]$ & 1110 & 616 & 494 \\
\hline ECG recorded in ambulance $-n(\%)$ & $4693(74.0)$ & $2540(71.9)$ & $1.28[1.10,1.49]$ & 8 & 4 & 4 \\
\hline ECG rhythm - n(\%) & & & & 873 & 512 & 361 \\
\hline Sinus rythm & $3882(70.8)$ & $2257(74.6)$ & $0.67[0.57,0.79]$ & & & \\
\hline Atrial fibrillation/flutter & $1249(22.8)$ & $648(21.4)$ & $1.19[1.01,1.41]$ & & & \\
\hline Other rythm ${ }^{\mathrm{e}}$ & $350(6.4)$ & $121(4.0)$ & $2.47[1.83,3.33]$ & & & \\
\hline ECG pattern - n(\%) & & & & 957 & 569 & 388 \\
\hline ST-elevation & $137(2.5)$ & $67(2.3)$ & $1.29[0.82,2.01]$ & & & \\
\hline ST-depression & $748(13.9)$ & $420(14.1)$ & $0.95[0.77,1.16]$ & & & \\
\hline T-wave inversion & $511(9.5)$ & $270(9.1)$ & $1.10[0.87,1.40]$ & & & \\
\hline Left bundle branch block & $325(6.0)$ & $181(6.1)$ & $0.97[0.72,1.31]$ & & & \\
\hline Blood Glucose measured - n(\%) & $1991(31.3)$ & $1034(29.2)$ & $1.25[1.08,1.43]$ & & & \\
\hline Blood glucose elevation $\geq 9.5 \mathrm{mmol} / \mathrm{l}$ & $749(37.6)$ & $402(38.9)$ & $0.89[0.70,1.14]$ & & & \\
\hline
\end{tabular}

${ }^{a}$ All patients category denoted with 25 th and 75 th percentiles, women and men with $99 \%$ - confidence intervals;VAS: visual analogue scale ${ }^{b}$ Odds ratio and $99 \%$ - confidence interval

'All patients and women category denoted with median (25th,75th percentiles) and percetage of deviating vital signs. Odds ratio and $99 \%$-confidence intervals calculated on number of deviating vital signs

Deviating vital signs: Respiratory rate $<8$ or $>25$ breaths/min; Oxygen saturation $<90 \%$; Heart rate $<40 / \mathrm{min}$ or $>120 / \mathrm{min}$; Systolic blood pressure $<90 \mathrm{~mm} / \mathrm{Hg}$; Diastolic blood pressure $>140 \mathrm{~mm} / \mathrm{hg}$; Body temperature $\left({ }^{\circ} \mathrm{C}\right)<35$ or $>41$; Reaction level scale (RLS) $>2$

'Electrocardiogram (ECG) rhythm and pattern recorded in Ambulance or in the ED within $4 \mathrm{~h}$

e Pacemaker rhythm, Av-block I,II,III, Ectopical atrial rhythm/takycardia, Idioventricular rhytm, Junctional rhythm, Pulseless electrical activity, Ventricular takycardia

reported in previous studies $[8,11,12]$. This is not unexpected since the incidence of chronic conditions associated with dyspnoea (e.g. COPD, heart failure, and coronary artery disease) increase with age [18]. Surprisingly, the majority had previously experienced dyspnoea. In our result, more than $60 \%$ of all patients were hospitalised. This is more than the entire EMS population in the same sampling area where the median age was 69 years and $50 \%$ of those taken to the ED were hospitalised [19].

Overall, $11 \%$ of our study patients died within 30 days, similar to previous studies $[8,9]$. The mortality risk was almost three times as high as in the total EMS population in the same area [19]. Furthermore, our result also found that men with dyspnoea as the main symptom had a higher mortality rate than women. We have no clear explanation to this finding. There was no significant difference between women and men in terms of their final diagnosis with the exception of a lower rate of pulmonary disease among women. But men had a more severe comorbidity and more frequently suffered from a previous history of a cardiovascular disease and renal disease. This may have contributed the higher mortality among men. From an overall population perspective 
Table 3 Distribution of patients across the 23 major ICD-10 code groups

\begin{tabular}{|c|c|c|c|}
\hline & All patients ${ }^{a}$ & Women & Men \\
\hline Chapters - n(\%) & 6354 & 3538 & 2816 \\
\hline I Certain infections and parasites diseases A00 - B99 & $161(3.0)$ & $75(2.6)$ & $1.40[0.92,2.10]^{\mathrm{b}}$ \\
\hline II Neoplasm C00 - D48 & $131(2.5)$ & $62(2.1)$ & $1.35[0.85,2.12]$ \\
\hline $\begin{array}{l}\text { III Diseases of the blood and blood forming organs } \\
\text { and certain diseases involving the } \\
\text { immuno-mechanisms D50 - D89 }\end{array}$ & $34(0.6)$ & $16(0.6)$ & $1.35[0.56,3.29]$ \\
\hline $\begin{array}{l}\text { IV Endocrine, nutritional and metabolic diseases } \\
\text { E00 - E90 }\end{array}$ & $42(0.8)$ & $25(0.9)$ & $0.82[0.36,1.84]$ \\
\hline V Mental and behavioural disorders F00 - F99 & $91(1.7)$ & $50(1.7)$ & $0.98[0.57,1.70]$ \\
\hline VI Diseases of the nervous system G00 - G99 & $29(0.5)$ & $17(0.6)$ & $0.85[0.32,2.24]$ \\
\hline VII Diseases of the eye and adnexa $\mathrm{H} 00$ - H59 & $0(0.0)$ & $0(0.0)$ & $0[0,0]$ \\
\hline $\begin{array}{l}\text { VIII Diseases of the eye and mastoid process } \\
\text { H60 - H95 }\end{array}$ & $0(0.0)$ & $0(0.0)$ & $0[0,0]$ \\
\hline IX Diseases of the circulatory system 100 - 199 & $1230(23.1)$ & $647(22.3)$ & $1.11[0.94,1.31]$ \\
\hline X Diseases of the respiratory system $J 00$ - $J 99$ & $2615(49.1)$ & $1476(50.8)$ & $0.86[0.75,0.99]$ \\
\hline XI Diseases of the digestive system K00 - K93 & $65(1.2)$ & $33(1.1)$ & $1.17[0.61,2.22]$ \\
\hline $\begin{array}{l}\text { XII Diseases of the skin and subcutaneous tissue } \\
\text { L00 - L99 }\end{array}$ & $6(0.1)$ & $3(0.1)$ & $1.20[0.15,9,85]$ \\
\hline $\begin{array}{l}\text { XIII Diseases of the musculoskeletal tissue and } \\
\text { connective tissue M00 - M99 }\end{array}$ & $51(1.0)$ & $37(1.3)$ & $0.45[0.20,1.02]$ \\
\hline XIV Diseases of the genitourinery system N00 - N99 & $69(1.3)$ & $30(1.0)$ & $1.57[0.84,2.95]$ \\
\hline XV Pregnancy, childbirth and puerperium O00 - O99 & $1(<0.1)$ & $1(<0.1)$ & $0[0,0]$ \\
\hline $\begin{array}{l}\text { XVI Certain conditions originating from the perinatal } \\
\text { period P00 - P96 }\end{array}$ & $0(0.0)$ & $0(0.0)$ & $0[0,0]$ \\
\hline $\begin{array}{l}\text { XVII Congenital malformations, deformation and } \\
\text { chromosomal malformations Q00 - Q99 }\end{array}$ & $1(<0.1)$ & $0(0.0)$ & $0[0,0]$ \\
\hline $\begin{array}{l}\text { XVIII Symptoms, signs and abnormal clinical findings, } \\
\text { not elsewhere classified R00 - R99 }\end{array}$ & $711(13.4)$ & $382(13.2)$ & $1.04[0.84,1.28]$ \\
\hline $\begin{array}{l}\text { XIX Injury, Poisoning and certain other consequences } \\
\text { of external causes S00 - T98 }\end{array}$ & $33(0.6)$ & $23(0.8)$ & $0.52[0.20,1.38]$ \\
\hline $\begin{array}{l}\text { XX External causes of morbidity and mortality } \\
\text { V00 - V99 }\end{array}$ & $1(<0.1)$ & $1(<0.1)$ & $0[0,0]$ \\
\hline XXI External causes to disease and death Y01 - Y98 & $1(<0.1)$ & $1(<0.1)$ & $0[0,0]$ \\
\hline $\begin{array}{l}\text { XXII Factors influencing health status and contact } \\
\text { with health services Z00 - Z99 }\end{array}$ & $48(0.9)$ & $23(0.8)$ & $1.31[0.62,2.76]$ \\
\hline XXIII Codes for special purposes U00-U99 & $4(0.1)$ & $3(0.1)$ & $0.40[0.20,7.84]$ \\
\hline
\end{tabular}

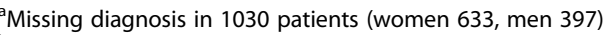

${ }^{b}$ Odds ratio and $99 \%$ - confidence interval

[20], it has been denoted that men have a greater vulnerability to cardiovascular diseases which is a reason to their higher mortality rate in general.

Patients attending EMS due to dyspnoea appear to have a five times higher risk of death than those with chest pain $[9,21]$. This is in agreement with other reports saying that regardless of the aetiology, patients who have dyspnoea in combination with other conditions have a poor prognoses [22]. Thus, dyspnoea should be perceived as a high-risk symptom and a strong predictor of an increased mortality risk [9, 11, 23, 24]. Further, respiratory failure has been defined as among the five First Hour Quinted emergency time-related pathologies. This means that immediate prehospital treatment and early diagnosis may be crucial in reducing the morbidity and mortality risk [6].

This should be attributed to the fact that patients only call EMSs when they cannot manage the situation themselves and indeed half of patients waited more than 2 days after symptom onset in our study. In one previous study [25], patients tried to ignore their symptoms or manage them (working through), leading to delays in calling EMSs; some of these patients even took a "waiting approach", while others were frustrated by their 
Table 4 Distribution of patients according to final diagnosis (ICD-10 code) among groups more than 30 patients

\begin{tabular}{|c|c|c|c|}
\hline & All patients ${ }^{a}$ & Women & Men \\
\hline Final diagnosis - n(\%) & 6354 & 3538 & 2816 \\
\hline 1. Cardiovascular disease & $1316(24.7)$ & $694(23.9)$ & $1.10[0.94,1.30]^{\mathrm{b}}$ \\
\hline a. Heart failure & $801(15.0)$ & $402(13.8)$ & $399(16.5)$ \\
\hline b. Ischemic heart disease & $154(2.9)$ & $70(2.4)$ & $84(3.5)$ \\
\hline c. Arrhythmia & $142(2.7)$ & $87(3.0)$ & $55(2.3)$ \\
\hline d. Pulmonary embolism & $123(2.3)$ & $81(2.8)$ & $42(1.7)$ \\
\hline 2. Pulmonary disease & $1311(24.6)$ & $780(26.9)$ & $0.77[0.65,0.91]$ \\
\hline a. Chronic obstructive pulmonary disease & $1088(20.4)$ & $656(22.6)$ & $432(17.9)$ \\
\hline b. Asthma bronchiale & $127(2.4)$ & $87(3.0)$ & $40(1.7)$ \\
\hline c. Other pulmonary diseases & $94(1.8)$ & $37(1.3)$ & $57(2.4)$ \\
\hline 3. Infection & $1172(22.0)$ & $607(20.9)$ & $1.15[0.97,1.37]$ \\
\hline a. Pulmonary & $912(17.1)$ & $469(16.1)$ & $443(18.3)$ \\
\hline b. Sepsis & $97(1.8)$ & $43(1.5)$ & $54(2.2)$ \\
\hline c. Ear, nose and throat and upper airways & $81(1.5)$ & $52(1.8)$ & $29(1.2)$ \\
\hline d. Other infection & $74(1.4)$ & $40(1.4)$ & $34(1.4)$ \\
\hline 4. Symptom diagnosis & $662(12.4)$ & $353(12.2)$ & $1.06[0.85,1.31]$ \\
\hline 5. Cancer & $138(2.6)$ & $66(2.3)$ & $1.32[0.85,2.01]$ \\
\hline a. Pulmonary & $89(1.7)$ & $49(1.7)$ & $40(1.7)$ \\
\hline b. Other localisation & $31(0.6)$ & $13(0.4)$ & $18(0.7)$ \\
\hline 6. Respiratory insufficiency & $129(2.4)$ & $79(2.7)$ & $0.76[0.47,1.21]$ \\
\hline 7. Psychiatric disorder & $90(1.7)$ & $49(1.7)$ & $1.01[0.58,1.74]$ \\
\hline 9. Urinary disease & $69(1.3)$ & $30(1.0)$ & $1.57[0.84,2.95]$ \\
\hline 10. Pleura Disease & $54(1.0)$ & $32(1.1)$ & $0.82[0.40,1.69]$ \\
\hline 11. Muscle skeletal pain & $44(0.8)$ & $32(1.1)$ & $0.45[0.19,1.07]$ \\
\hline 12. Organ failure & $39(0.7)$ & $23(0.8)$ & $0.84[0.36,1.95]$ \\
\hline 13. Gastrointestinal disease & $33(0.6)$ & $18(0.6)$ & $1.00[0.41,2.47]$ \\
\hline 14. Anaemia & $33(0.6)$ & $15(0.5)$ & $1.44[0.59,3.56]$ \\
\hline
\end{tabular}

${ }^{a}$ Missing diagnosis in 1030 patients (women 633, men 397)

b Odds ratio with $99 \%$ - confidence interval, subcategories with percentage

symptoms. This information is vital for consideration in the meeting between the PEN and patient.

The dyspnoea experience varies across people, and one can assume that some degree of tolerance to dyspnoea already existed in our patient group due to their comorbidities (e.g. COPD, heart failure, and hypertension). This is supported by earlier studies $[10,23]$ in which this patient group was characterised by poor health. Dyspnoea, to some extent, is a part of natural ageing and results in a decreasing degree of physical capacity; thus, it is not always explained by a specific illness or related to comorbidity presence. It may also be that elderly people are more tolerant and do not want to interfere or be perceived as disruptive. Thus, they may understate their symptom experience and severity when finally calling for help. This makes it even more difficult for both dispatchers and the PEN to determine disease severity [11].
Almost one in four patients had atrial fibrillation and a few had signs of myocardial ischemia on ECG, indicating that a cardiac pathology was not uncommon. This is most likely explained by the high degree of cardiovascular comorbidity reported in such populations [26-29]. Atrial fibrillation and acute heart failure are often seen in combination, and since heart failure is one of the dominating aetiologies behind dyspnoea, this was an expected finding. Based on previous history, one may assume that when atrial fibrillation occurred, it was most often previously known. Dyspnoea due to acute heart failure and the presence of ECG-related abnormalities, such as ventricular or supraventricular arrhythmia, bradycardia, or ongoing myocardial ischemia, may all be indicators of an increased risk of early hospital death [30].

One in four patients experienced pain, which may be important from a diagnostic as well as therapeutic perspective. The pain experience was mostly related to 
breathing-related chest discomfort, thoracic pain, chest wall pain, shoulder pain, or pain due to other unclear reasons. The presence of pain in dyspnoea patients has previously been reported $[9,21,22,31]$, mostly in the form of chest pain as a result of underlying causes including pulmonary embolism myocardial infarction, pneumonia and panic disorder.

A large proportion had hyperglycaemia. This may be an alarming sign also among patients with dyspnoea. Hyperglycaemia is a marker of acute stress response which, especially in nondiabetic patients, is associated with higher rates of in-hospital complications and mortality $[15,32]$.

Although only $11 \%$ had time critical final diagnoses, a much larger proportion of these patients will be regarded as having a time-critical condition in the acute phase since the majority had abnormal VS, primarily an abnormal respiratory rate and oxygen saturation. This requires advanced knowledge from the PENs who is caring for patients with dyspnoea, as abnormal vital parameters may be a sign of a number of different serious conditions; both cardiogenic, pulmonary and other aetiologies of acute respiratory failure. This highlights the importance of early recognition of the patients condition and directed treatment already at an early stage by EMS, as it might be crucial for the final outcome [33-35]. It has previously been reported that acute ill patients (including those with dyspnoea) admitted thorough ED [36] with abnormal vital parameters, have an increased risk of death. The most powerful predictors were abnormal respiratory rate, oxygen saturation and Glasgow Coma scale (GCS).

\section{Clinical implications}

Our results suggest that $11 \%$ of all patients seen by PENs due to dyspnoea have time critical diagnosis and $11 \%$ will die during the subsequent 30 days. Available information from age, sex, comorbidity and clinical findings including vital parameters, ECG recordings, blood glucose measurements and other symptoms may form the basis for the building of future decision support tools in order to differentiate patients with high and low risk for future adverse events.

\section{Strengths and limitations}

The major strength of our study is that data were collected from a relatively large representative sample. While the data were collected from a mix of urban and rural areas, the study itself is limited to a specific region of Sweden (southwest) which may impede the degree of generalisability of the findings to other settings. People living in the northern part of Sweden have greater difficulties in accessing EMSs and longer transport distances, which may lead to result variations.
Furthermore, due to the study design, the data had to be retrospectively collected from patient records, and important clinical parameters such as VS may have been measured but never recorded. In both EMS and hospital records, the documentation was sometimes insufficient. Likewise, it is possible that patients with other main symptoms who still have dyspnoea may have been classified into other ESS codes (not only ESS 04) by the PEN, as dyspnoea is also present in other conditions such as chest pain.

Information on the final diagnosis was missing in 1030 of all missions. Such cases were those left on- scene in whom there was no information on final diagnosis and patients who were brought to hospital and directly sent home from the Emergency Department, since some of them were never assessed by a physician. However, the present study was conducted in accordance with a paper by Kaji et al. [37], with the aim of reducing the bias associated with medical record reviews.

\section{Conclusions}

Dyspnoea, as the main symptom, constituted approximately $9 \%$ of all the EMS missions in our study. A majority of the patients taken to hospital with dyspnoea as the main symptom were hospitalised and more than 400 different final diagnoses were observed, of which $11 \%$ were regarded as time-critical. A very high proportion (84\%) had previously suffered from dyspnoea, which may explain why more than half showed delays greater than 2 days from symptom onset to EMS contact. High comorbidity values may contribute to this finding. Likewise, that patients call for help only when the situation is truly unmanageable makes them even more vulnerable. Dyspnoea, as the main symptom, is associated with a high risk of death, and $11 \%$ of all patients were dead within 30 days. However, more than half of these patients had abnormal vital parameters at the time of PEN assessment. This knowledge is important, not only for EMSs, but also for clinicians and those responsible for the provision of education in different emergency courses.

\section{Supplementary information}

Supplementary information accompanies this paper at https://doi.org/10. 1186/s12873-020-00363-6.

Additional file 1. The supplementary file describes in more detail deviating vital signs Red/Orange level according to RETTS-A (2017 version) and RETTS ESS 04 (main symptom of dyspnoea).

\footnotetext{
Abbreviations

COPD: Chronic obstructive pulmonary disease; ECG: Electrocardiogram; ED: Emergency department; EMS: Emergency medical service; ESS: Emergency signs and symptoms; ICD-10: International Statistical Classification of Diseases and Related Health Problems - 10th revision; PEN: Prehospital emergency nurse; RETTS-A: Rapid emergency triage and treatment system for adults; VS: Vital signs
} 


\section{Acknowledgements}

The authors wish to acknowledge the Ambulance and Prehospital Emergency Care, Sahlgrenska University Hospital in Gothenburg, Sweden and Ambulance and Prehospital Emergency Care, Södra Älvsborg hospital in Borås, Sweden for providing data on EMS assignments. We also acknowledge the help extended by Jonny Lindqvist, Region Västra Götaland, Gothenburg, Sweden in creating the data protocol.

\section{Authors' contributions}

WK, CA, JH, and LP developed the design and the research protocol. WK, CA, and $\mathrm{JH}$ created the data forms. WK collected the data. CM supervised the statistical analyses and was discussed with WK, CA and JH. WK and JH wrote the first draft of the manuscript. WK, CA, JH, LP, and CM supervised and analysed the data and their interpretation. All the authors participated in the final drafting of the manuscript and have read and approved the final manuscript.

\section{Funding}

WK received funding from the University of Borås, Sweden. The funder did not have any role in the study design, aim, or process. Open access funding provided by University of Boras.

\section{Availability of data and materials}

The datasets analysed during the current study are available from the corresponding author on reasonable request.

\section{Ethics approval and consent to participate}

The design of the study was approved by the Regional Ethics Committee in Gothenburg, Sweden (Dnr 989-17). All the procedures performed in this study were in accordance with the ethical standards of the Declaration of Helsinki [38]. Consent were obtained from chief executive officers in the participating EMS organisations for reviewing patient records and to use the data for analysis. Informed consent for participation was not required. This is mostly not recommended by Ethical Review Boards in Sweden for the following reasons:

1) Individual patients could never be identified since their identification number was translated to a code. Their integrity, therefore, remained intact.

2) Some of the most seriously ill patients could never be contacted retrospectively, since they had either died or were in a very poor clinical condition. This would increase the risk of selection bias, thereby, hampering the reliability of the data.

3) Approaching patients with these issues may create more anxiety than satisfaction and may, therefore, be regarded as unethical.

\section{Consent for publication}

Not applicable.

\section{Competing interests}

The authors declare that they have no competing interests.

\section{Author details}

'PreHospen- Centre for Prehospital Research, Faculty of Caring, Work Life and Social Welfare, University of Borås, SE- 50190 Borås, Sweden. ${ }^{2}$ Faculty of Caring Science, Work Life and Social Welfare, University of Borås, Borås, Sweden. ${ }^{3}$ Department of Molecular and Clinical Medicine, Sahlgrenska Academy, University of Gothenburg, Gothenburg, Sweden.

Received: 24 March 2020 Accepted: 21 August 2020

\section{Published online: 28 August 2020}

\section{References}

1. Pittet V, Burnand B, Yersin B, Carron PN. Trends of pre-hospital emergency medical services activity over 10 years: a population-based registry analysis. BMC Health Serv Res. 2014;14:380

2. Parshall MB, Schwartzstein RM, Adams L, Banzett RB, Manning HL, Bourbeau J, et al. An official American Thoracic Society statement: update on the mechanisms, assessment, and management of dyspnea. Am J Respir Crit Care Med. 2012;185:435-52.
3. Pooler C. Living with chronic lower pulmonary disease: disruptions of the embodied phenomenological self. Glob Qual Nurs Res. 2014;1: 2333393614548762

4. Berliner D, Schneider N, Welte T, Bauersachs J. The differential diagnosis of dyspnea. Dtsch Arztebl Int. 2016;113:834-45.

5. Gori CS, Magrini L, Travaglino F, Di Somma S. Role of biomarkers in patients with dyspnea. Eur Rev Med Pharmacol Sci. 2011;15:229-40.

6. Krafft T, Garcia Castrillo-Riesgo L, Edwards S, Fischer M, Overton J, Robertson-Steel I, et al. European emergency data project (EED project): EMS data-based health surveillance system. Eur J Pub Health. 2003;13:85-90.

7. Christie A, Costa-Scorse B, Nicholls M, Jones P, Howie G. Accuracy of working diagnosis by paramedics for patients presenting with dyspnoea. Emerg Med Australas. 2016;28:525-30

8. Lindskou TA, Pilgaard L, Sovso MB, Klojgard TA, Larsen TM, Jensen FB, et al. Symptom, diagnosis and mortality among respiratory emergency medical service patients. PLoS One. 2019;14:e0213145.

9. Botker MT, Stengaard C, Andersen MS, Sondergaard HM, Dodt KK, Niemann $\mathrm{T}$, et al. Dyspnea, a high-risk symptom in patients suspected of myocardial infarction in the ambulance? A population-based follow-up study. Scand Trauma Resusc Emerg Med. 2016;24:15.

10. Hayen A, Herigstad M, Pattinson KT. Understanding dyspnea as a complex individual experience. Maturitas. 2013;76:45-50.

11. Kelly AM, Holdgate A, Keijzers G, Klim S, Graham CA, Craig S, et al. Epidemiology, prehospital care and outcomes of patients arriving by ambulance with dyspnoea: an observational study. Scand J Trauma Resusc Emerg Med. 2016;24:113

12. Prekker ME, Feemster LC, Hough CL, Carlbom D, Crothers K, Au DH, et al. The epidemiology and outcome of prehospital respiratory distress. Acad Emerg Med. 2014;21:543-50.

13. Suserud BO. A new profession in the pre-hospital care field--the ambulance nurse. Nurs Crit Care. 2005;10:269-71.

14. Widgren BR, Jourak M. Medical emergency triage and treatment system (METTS): a new protocol in primary triage and secondary priority decision in emergency medicine. J Emerg Med. 2011;40:623-8.

15. Sud M, Wang X, Austin PC, Lipscombe LL, Newton GE, Tu JV, et al. Presentation blood glucose and death, hospitalization, and future diabetes risk in patients with acute heart failure syndromes. Eur Heart J. 2015:36:924-31.

16. Wibring K, Magnusson C, Axelsson C, Lundgren P, Herlitz J, Andersson HM. Towards definitions of time-sensitive conditions in prehospital care. Scand J Trauma Resusc Emerg Med. 2020;28:7.

17. Sovso MB, Christensen MB, Bech BH, Christensen HC, Christensen EF, Huibers L. Contacting out-of-hours primary care or emergency medical services for time-critical conditions - impact on patient outcomes. BMC Health Serv Res. 2019:19:813.

18. Kelly AM, Keijzers G, Klim S, Graham CA, Craig S, Kuan WS, et al. An observational study of dyspnea in emergency departments: the Asia, Australia, and New Zealand dyspnea in emergency departments study (AANZDEM). Acad Emerg Med. 2017;24:328-36.

19. Magnusson C, Herlitz J, Axelsson C. Patient characteristics, triage utilisation, level of care, and outcomes in an unselected adult patient population seen by the emergency medical services: a prospective observational study. BMC Emerg Med. 2020:20:7.

20. Crimmins EM, Shim H, Zhang YS, Kim JK. Differences between men and women in mortality and the health dimensions of the morbidity process. Clin Chem. 2019;65:135-45.

21. Pedersen CK, Stengaard C, Friesgaard K, Dodt KK, Sondergaard HM, Terkelsen CJ, et al. Chest pain in the ambulance; prevalence, causes and outcome - a retrospective cohort study. Scand J Trauma Resusc Emerg Med. 2019:27:84.

22. McConaghy JR, Oza RS. Outpatient diagnosis of acute chest pain in adults. Am Fam Physician. 2013;87:177-82.

23. Huijnen $B$, van der Horst $F$, van Amelsvoort $L$, Wesseling $G$, Lansbergen $M$, Aarts $\mathrm{P}$, et al. Dyspnea in elderly family practice patients. Occurrence, severity, quality of life and mortality over an 8-year period. Fam Pract. 2006; 23:34-9.

24. Berraho M, Nejjari C, El Rhazi K, Tessier JF, Dartigues JF, Barberger-Gateau P, et al. Dyspnea: a strong independent factor for long-term mortality in the elderly. J Nutr Health Aging. 2013;17:908-12.

25. McCabe PJ, Rhudy LM, Chamberlain AM, DeVon HA. Fatigue, dyspnea, and intermittent symptoms are associated with treatment-seeking delay for 
symptoms of atrial fibrillation before diagnosis. Eur J Cardiovasc Nurs. 2016; 15:459-68.

26. Odigie-Okon E, Jordan B, Dijeh S, Wolff A, Dadu R, Lall P, et al. Cardiac injury in patients with COPD presenting with dyspnea: a pilot study. Int J Chron Obstruct Pulmon Dis. 2010;5:395-9.

27. Wilhelmsen L, Rosengren A, Lappas G. Hospitalizations for atrial fibrillation in the general male population: morbidity and risk factors. J Intern Med. 2001; 250:382-9.

28. Ariansen I, Edvardsen E, Borchsenius F, Abdelnoor M, Tveit A, Gjesdal K. Lung function and dyspnea in patients with permanent atrial fibrillation. Eur J Intern Med. 2011;22:466-70.

29. Vanfleteren LE, Franssen FM, Uszko-Lencer NH, Spruit MA, Celis M, Gorgels AP, et al. Frequency and relevance of ischemic electrocardiographic findings in patients with chronic obstructive pulmonary disease. Am J Cardiol. 2011; 108:1669-74.

30. Beygui F, Castren M, Brunetti ND, Rosell-Ortiz F, Christ M, Zeymer U, et al. Pre-hospital management of patients with chest pain and/or dyspnoea of cardiac origin. A position paper of the Acute Cardiovascular Care Association (ACCA) of the ESC. Eur Heart J Acute Cardiovasc Care. 2015;9: 59-81.

31. Johansson EL, Ternesten-Hasseus E, Olsen MF, Millqvist E. Respiratory movement and pain thresholds in airway environmental sensitivity, asthma and COPD. Respir Med. 2012;106:1006-13.

32. Schuetz P, Kennedy M, Lucas JM, Howell MD, Aird WC, Yealy DM, et al. Initial management of septic patients with hyperglycemia in the noncritical care inpatient setting. Am J Med. 2012;125:670-8.

33. Mebazaa A, Tolppanen H, Mueller C, Lassus J, Disomma S, Baksyte G, et al. Acute heart failure and cardiogenic shock: a multidisciplinary practical guidance. Intensive Care Med. 2016;42:147-63.

34. Hensel M, Strunden MS, Tank S, Gagelmann N, Wirtz S, Kerner T. Prehospital non-invasive ventilation in acute respiratory failure is justified even if the distance to hospital is short. Am J Emerg Med. 2019;37:651-6.

35. Nielsen VM, Madsen J, Aasen A, Toft-Petersen AP, Lubcke K, Rasmussen BS, et al. Prehospital treatment with continuous positive airway pressure in patients with acute respiratory failure: a regional observational study. Scand J Trauma Resusc Emerg Med. 2016;24:121.

36. Barfod C, Lauritzen MM, Danker JK, Soletormos G, Forberg JL, Berlac PA et al. Abnormal vital signs are strong predictors for intensive care unit admission and in-hospital mortality in adults triaged in the emergency department - a prospective cohort study. Scand J Trauma Resusc Emerg Med. 2012;20:28.

37. Kaji AH, Schriger D, Green S. Looking through the retrospectoscope: reducing bias in emergency medicine chart review studies. Ann Emerg Med. 2014;64:292-8.

38. World Medical A. World medical association declaration of Helsinki: ethical principles for medical research involving human subjects. JAMA. 2013;310: 2191-4.

\section{Publisher's Note}

Springer Nature remains neutral with regard to jurisdictional claims in published maps and institutional affiliations.

Ready to submit your research? Choose BMC and benefit from:

- fast, convenient online submission

- thorough peer review by experienced researchers in your field

- rapid publication on acceptance

- support for research data, including large and complex data types

- gold Open Access which fosters wider collaboration and increased citations

- maximum visibility for your research: over $100 \mathrm{M}$ website views per year

At BMC, research is always in progress.

Learn more biomedcentral.com/submissions 